“I'm Scared of the Disappointment": Young Adult Smokers' Relational Identity Gaps and Management Strategies as Sites of Communication Intervention

\author{
Samantha J. Stanley \\ University of Maryland \\ Department of Communication \\ Margaret Jane Pitts \\ University of Arizona \\ Department of Communication
}




\begin{abstract}
While cigarette smoking is decreasing among young adults, rates of nicotine consumption through other devices, most notably electronic cigarettes, are on the rise. Framed by communication theory of identity, this study examines young adult smokers' experiences with relational others in regards to their smoking. Focus group discussions and individual interviews convened with 20 young adult cigarette and electronic cigarette smokers revealed identity gaps implicating the relational layer of identity, including personal-relational, enacted-relational, and personal-enacted-relational identity gaps. Participants used communicative and behavioral strategies to manage relational discrepancies. The documented identity gaps and management strategies present opportunities for targeted smoking cessation interventions that amplify dissonance created through identity gaps as a motivational tactic.
\end{abstract}




\section{"I'm Scared of the Disappointment": Young Adult Smokers' Relational Identity Gaps and Management Strategies as Sites of Communication Intervention}

\section{Introduction}

Rates of cigarette smoking declined from $20.9 \%$ in 2005 to $15.1 \%$ in 2015 among adults over 18, but decreased most markedly in young adults ages 18-24 (Jamal et al., 2016). However, youth and young adult nicotine consumption through other devices (e.g., electronic cigarettes, hookah, etc.) is increasing at a rapid rate (U.S. Department of Health and Human Services [DHHS], 2016; Singh et al., 2016). Young adults are especially vulnerable to negative effects of nicotine exposure including addiction and the uptake of other addictive substances (DHHS, 2016). Young adulthood is not only a time of experimentation and identity change (Arnett, 2000), but is also a time when people begin to develop lifelong health behaviors and habits (Rath, Villanti, Abrams, \& Vallone, 2012).

Communication and identity are central to changing health beliefs and behaviors. Identity change often precedes behavior change in the context of addictive behaviors. For example, cigarette smoker identities influence quit attempts and long-term abstinence (Tombor et al., 2015). As established in Hecht's (1993) communication theory of identity (CTI), communication and identity are inseparable. The interdependent nature of communication and identity and their centrality to health behaviors make them useful concepts for understanding smoking maintenance and cessation, especially among young adults.

During a larger study utilizing focus groups and interviews, it became apparent that young adult smokers' identities, communication, and health behaviors were highly influenced by relational others' responses to their smoking (Stanley, 2016). Indeed, several identity gaps implicating interpersonal relationships emerged. Therefore, the purpose of this study was to 
apply CTI to examine data previously collected in order to uncover relational identity gaps young adult smokers experience and the strategies they enact to manage them. With this purpose in mind, we hope that relational identity gaps and management strategies can be targeted in future health messages to motivate behavior change among this population. Interventions with relational others may be especially potent at this point in the lifespan where some young adults are positioned between taking on a "smoker" or "nonsmoker."

\section{Interpersonal Relationships and Smoking}

Interpersonal relationships influence smoking initiation, maintenance, and cessation throughout the lifespan. During adolescence, some friendships are formed and maintained in part because of similar cigarette use, and adolescents are likely to change their smoking behavior to converge with friends' smoking behaviors over time (Wang, Hipp, Butts, Jose, \& Lakon, 2016). Alternatively, adolescents cite being accountable to parents and siblings as a reason to resist tobacco (Pettigrew, Miller-Day, Krieger, \& Hecht, 2011). Young adults exposed to smoking by social contacts including family and friends are more likely to initiate or maintain smoking than those who are unexposed to smoking (Freedman, Nelson, \& Feldman, 2012). Even for adults, ecigarette initiation most frequently begins with friends (Coleman et al., 2015).

The process of quitting is also relationally driven. For example, adult smokers who engage in social networking sites dedicated to smoking cessation receive social support and increase the number and depth of social ties, all of which improve smoking cessation selfefficacy (Phua, 2013). Adolescents who view anti-smoking ads depicting in-group peer members more strongly believe a key antismoking belief endorsed in the ad (Moran \& Sussman, 2014). Finally, college students who smoke identify social factors like disapproval of their smoking by family and friends as among motivators to quit (Berg et al., 2010). To understand the 
interrelation of smoking, identity, communication, and relationships we turn to CTI (Hecht, 1993)=

\section{Communication Theory of Identity}

According to CTI, identity is created, shaped, and expressed through communication essentially making identity a communication construct (Hecht, 1993; Jung \& Hecht, 2004). Identity occurs at four different loci: within a person, within an interaction, within a relationship, and within a group (Hecht, Warren, Jung, \& Krieger, 2005). These loci correspond to the four layers of identity: personal, enacted, relational, and communal. The personal layer of identity represents a person's self-concept (Hecht et al., 2005). The enacted layer locates identity in the expression of communication with others (Hecht, 1993). The relational layer of identity describes the co-creation and negotiation of identity through roles and social interactions. Relational identity has four levels. First, individuals internalize others' perceptions to develop and shape their own identity; this is known as ascribed relational identity. Second, identity is formed according to the social roles one takes on in relationships with others (e.g., I am a sister, student). Third, identity is formed according to the multiple roles individuals may hold in relation to each other (e.g., I am a mother which impacts my job as a teacher). Finally, a relationship can be a unit of identity (e.g., a couple as a unit) (Jung \& Hecht, 2004). The fourth layer of identity is the communal frame, which encompasses larger social groups such as cultures and communities.

Identity Gaps. The four layers of identity interpenetrate and influence each other such that the negotiation of one layer of identity necessarily impacts the other layers (Hecht et al., 2005). Identity is relatively unproblematic when all layers are aligned but layers do not always coexist in harmony. When layers are contradictory an identity gap occurs (Hecht, 2014). Identity 
gaps can occur through external interactions and are an inevitable part of communication (Jung \& Hecht, 2004). The experience of identity gaps is marked by feelings of dissonance such that people likely have some awareness of internal and external inconsistencies (Festinger, 1962). Generally speaking, identity gaps are problematic. The presence of identity gaps can decrease communication and relationship satisfaction, decrease communication appropriateness and effectiveness, cause people to feel misunderstood, lead to topic avoidance, and is linked with depression (Jung \& Hecht, 2004, 2008).

While identity gaps are associated with negative outcomes there is also speculation that identity gaps may be useful in promoting health if they motivate an individual to change (Hecht, 2014; Hecht \& Choi, 2012). As a "source of expectation and motivation" identities also “prescribe modes of conduct” (Hecht et al., 2005, p. 264; Hecht et al., 2003, p. 231). If identity gaps and their negative outcomes help people to recognize differences between, for example, their enacted behaviors (smoking) and their self-concept (nonsmoker), then people may be motivated to change their behaviors to match their self-concept and eliminate the identity gap. The speculated usefulness of identity gaps is consistent with research showing a shift in identity is key to health behavior change (Kearney \& O’Sullivan, 2003).

Identity Gaps and Smoking. Identity gaps are more likely to occur among those who face discrimination or devaluation (Jung \& Hecht, 2008). We believe that people who smoke cigarettes are likely to experience identity gaps in part because of discrimination against smokers. For example, smoke-free policies require the separation of smokers from nonsmokers in public spaces which may lead to loss of acceptance from others and create feelings of segregation among smokers (Ritchie, Amos, \& Martin, 2010). Additionally, smoking denormalization strategies "deliberately reframe smoking as socially unacceptable" and lead 
nonsmokers to reject the behavior of smoking so that smoking becomes a discrediting attribute to those who smoke (McCool, Hoek, Edwards, Thomson, \& Gifford, 2013, p. 555). When people have a devalued layer of identity they may attempt to hide their "true" identity and take on a "socially acceptable" identity to appease relational others. This inherently leads to identity gaps. Therefore, CTI is a particularly useful theory for exploring the impact of smoking on relationships.

\section{Current Study}

The current study was conducted as part of a Master's thesis investigating how smoking influences young adult smokers' identities. Over the course of data collection, participants' smoking identities seemed bound with their relational identities in ways that suggested important identity gaps. Given the attention that young adult smokers drew to relational identity gaps we believe that relational identity gaps and strategies to manage these gaps can provide useful points of entry for future smoking cessation interventions. Therefore, this analysis focuses on identity gaps emerging within the relational layer of identity. We note, however, that identity gaps were evident at all layers of identity examined in the larger study. The following research questions guided analysis:

RQ1: What identity gaps implicating the relational layer of identity do young adult smokers experience?

RQ2: What strategies do young adult smokers use to manage identity gaps involving the relational layer of identity?

\section{Methods}

Focus group discussions and individual interviews were used to elicit participants' lived experiences as smokers. Focus group discussions simulate the negotiation of meaning between 
interactants that occurs in everyday life (Duggleby, 2005; Zorn, Roper, Broadfoot, \& Weaver, 2006). It is through this negotiation of meaning that participants understand their own identities and recognize moments of identity tension where gaps have emerged in their lives. Thus, focus group discussions may also benefit participants by increasing awareness of their own behaviors and illuminating any gaps. Participants who belong to stigmatized groups may also feel empowered by engaging with other members of the same group (Zorn et al., 2006). While focus group discussions allow the researcher to get at a shared sense of experience, individual interviews offer greater depth and personal insight at the individual level. We pursued individual interviews for several reasons. In the main, following the principle of theoretical sampling (Glaser, 1978), individual interviews were used to collect additional data to follow up on points emerging from group discussions. Theoretical sampling is a way of "checking on the emerging conceptual framework" by affording the qualitative analyst the opportunity to "make shifts of plan and emphasis early in the research process so that the data gathered reflects what is occurring in the field rather than speculation about what cannot or should have been observed" (Glaser, 1978, pp. 38-39). In short, we were purposive in our use of individual interviews in order to test and advance our theoretical claims. Individual interviews may also benefit participants by creating a less public, and more comfortable opportunity for individuals to share disclosures that are potentially face threatening (Rubin \& Rubin, 1995). The combination of focus group discussion and individual interviews allowed us to triangulate individual and groupbased data. Collecting data via focus groups and individual interviews also offered the additional benefit of flexibility in scheduling in order to accommodate all potential participants with a convenient time and location.

\section{Participants and Recruitment}


The lead author recruited participants through flyers distributed via university email lists, posted in smoke shops, and posted on social media sites. We also recruited via network sample by offering participants a small financial incentive to recruit others. Potential participants completed an on-line screening survey, which ensured that all participants were ages 18-25 and currently smoked cigarettes or e-cigarettes “occasionally" or "often.” All participants were offered a small financial compensation for their time.

In total, 20 young adult smokers (18 men and 2 women) ages 19-24 (median age 21) took part in this study. We recognize the discrepancy between male and female participants presents a major limitation to this study. We suspect the discrepancy is, in part, due to greater stigma associated with female than male smokers. On average, participants began smoking at age 17 and represented a wide range of smoking habits: eight smoked cigarettes regularly, seven smoked cigarettes and e-cigarettes regularly, three were former cigarette smokers who currently smoked e-cigarettes, two smoked cigarettes "socially" and smoked e-cigarettes regularly. Two participants were not in college, one was a first-year student, five were sophomores, five were juniors, and seven were seniors in college.

Thirteen individuals participated in four 60-minute focus group discussions. During the focus group consent process, participants indicated willingness to engage in a future follow-up interview. Of the 13 focus group participants, three were identified as potentially rich information sources and invited to participate in a follow-up individual interview. An additional seven participants took part in individual interviews only.

\section{Instruments and Procedure}

Focus groups and interviews were conducted over three months in spring 2016. The lead author served as focus group moderator and interviewer. A trained undergraduate assistant was 
present at all focus groups to welcome participants, collect consent forms, and take notes unobtrusively. During individual interviews only the lead author was present. Focus groups and interviews were audio recorded.

The lead author used nondirective open-ended questions to elicit participant responses and probing to generate detailed responses. Sample questions used in both focus groups and individual interviews included: 1) Tell me about being a smoker? What does that mean in your day-to-day living? 2) In what circumstances are you more and less likely to identify as a smoker? 3) How do people in your social network respond to your smoking? ${ }^{1}$ The focus group protocol was modified only slightly to guide the seven individual interviews. The lead author created an individualized interview guide for the three focus group participants who participated in the follow up individual interviews. At the end of each session, the lead author offered all participants an opportunity to ask questions, dispensed compensation, and distributed a list of tobacco counseling resources. Focus groups and interviews were held until theoretical saturation occurred, in this case when all 11 possible identity gaps appeared in the data (O'Reilly \& Parker, 2012). Because we applied CTI as a sensitizing framework, theoretical saturation refers to the point in qualitative data collection that no new themes emerge and all a priority categories are identified. Specifically, we used theoretical sampling (Glaser, 1978) to ensure all identity gaps were surfaced in individual and follow-up interviews. While all eleven identity gaps were uncovered, this paper focuses solely on identity gaps that implicate the relational layer of identity as they were the most prevalent in the data. ${ }^{2}$

\footnotetext{
${ }^{1}$ The full protocol is available upon request.

${ }^{2}$ We do not include instances of communal-relational identity gaps. Only 13 instances of communal-relational identity gaps were coded in the data. Given the infrequency of communalrelational gaps compared with other identity gaps, it seems of less consequence to young adult smokers.
} 


\section{Data Analysis}

The lead author transcribed all audio recordings verbatim resulting in 227 pages of data. Participants were assigned a two-unit identification number to maintain confidentiality (i.e., 2P2 refers to focus group two, participant two; IP2 refers to interview only, participant two). Then, the lead author read the body of transcripts holistically and began coding transcripts using NVIVO software. The lead author took an iterative approach to data analysis, cycling between the data and theoretical framework to allow CTI to guide analysis (Tracy, 2013). The lead author began analyzing via open coding, which requires reading transcripts line-by-line to identify meaningful chunks of data that answer the research questions and assigning short descriptors to them. After completing first cycle coding, coauthors began second cycle coding, which requires clustering together similar codes to form categories that answer research questions (Saldaña, 2014). Throughout the coding process coauthors drew upon CTI as a sensitizing framework and discussed any discrepancies in coding until we reached agreement that the codes reflected the data.

\section{Findings}

Our findings demonstrate that young adult smokers experience relational identity gaps yet enact strategies to manage these gaps. Many of the relationships affected by identity gaps were with emotionally close others, especially family members and romantic partners. The impact of smoking on these relationships is succinctly captured in three identity gaps that participants frequently experience (e.g., enacted-relational, personal-relational, personal-enactedrelational). Participants sought to manage identity gaps through communicative and behavioral strategies, which they most often enacted when meeting new people and communicating with family members. These and other findings are detailed below. 


\section{Young Adult Smokers' Relational Identity Gaps}

The relational layer of identity captures the negotiation of identity through social interaction. Research question one sought to identify relational identity gaps experienced by young adult smokers.

Enacted-relational identity gaps. Enacted-relational identity gaps are marked by discrepancies in an individual's behavior, through which he attempts to influence others' perceptions of him, and the identity ascribed to him by others. Enacted-relational identity gaps were the most prevalent gap expressed in this sample with 80 instances coded. These gaps emerged in relationships with family members, romantic partners, and authority figures with whom participants enacted a nonsmoker identity to avoid being ascribed a smoker identity.

Gaps in family relationships. Enacted-relational identity gaps emerged most frequently in family relationships with 57 instances expressed by 16 participants. Many participants hid their smoking from family members to avoid negative reactions. 3P1 does not "want my parents or anybody knowing that I smoke cigarettes. I think I've wanted to tell them but, just couldn't get it out of me because, I'm scared of the disappointment?” Despite smoking for six years, 1P1 has managed to hide his smoking from his family because his parents "have a very negative connotation of smoking. Really don't like it... they told me that if I ever started smoking that they'd disown me too. So that was some (.) good motivation to keep it from them." Hiding their smoking from family members seemed easy for young adults in this sample. 4P5 said hiding his smoking from his family is not difficult “unless I'm stupid and I'm comin' home smelling like it or leave 'em [cigarettes] around but, yeah I don't see it having to ever be a conversation with them. Cause it wouldn't go well." 
Participants frequently cited parents' concern for their health as a reason to maintain enacted-relational gaps. 4P5 rationalized not telling his mother about his smoking because his grandfather died of lung cancer and so she “definitely doesn't like smoking." 4P2's father was diagnosed with lung cancer and 4P2 believes that if he disclosed his smoking to his parents they would "be pissed, they'd be really pissed." Fear of an angry reaction drove IP3 to hide his ecigarette use from his parents because "my dad's a doctor so he would be super pissed, even though it's [e-cigarettes] apparently healthier than cigarettes." Instead of avoiding an angry reaction, IP5 does not tell his parents he smokes because "I don't want to make them worried" about the potential health consequences resulting from his smoking.

Gaps in relation to romantic partners. Enacted-relational identity gaps also arose with potential or current romantic partners with 11 instances expressed by eight participants. IP1 would be least likely to identify as a smoker "meeting girls? You don't want to tell girls you smoke cigarettes...Because it smells bad...gives you bad breath.” 3P1 recalled a girl who "wouldn't kiss me, hug me, whatever, if I had smoked a cigarette" but would risk not hanging out with her "to smoke a cigarette and go to the bathroom and rinse my mouth out and stuff and she still would catch me."

Gaps in relation to authority figures. Participants also purposely maintained enactedrelational identity gaps with authority figures, including employers, doctors, and professors. Enacted-relational gaps with authority figures were expressed in 12 instances by 11 participants. Participants seemed especially eager to avoid being ascribed the characteristics of a smoker by "adult figures or respectable figures someone you look up to: a professor, a teacher, mentor" (2P3). For IP6, "unless a potential employer asks then I won't tell [that I smoke]" because of the conflict caused by the perception that smokers "always have to go out and take a smoke break." 
Participants were also reluctant to disclose their smoking to health care providers. Some chose not to disclose because "I don't want that to affect how they look at my health. I want them to think of me as just a normal everyday 20-year-old" (3P1). Others were reluctant to disclose to health care providers because "they tell you to stop" (4P2) and "give me the whole lecture like why you shouldn't but it's like I already know that so I don't wanna go through that" (4P4).

Personal-relational identity gaps. Personal-relational identity gaps are marked by a discrepancy between an individual's self-concept and the identity that other people ascribe to him or her. There were 40 coded instances of personal-relational identity gaps expressed by 17 participants. Participants who experienced personal-relational identity gaps felt they were ascribed characteristics by nonsmokers that did not match their personal identity, often noting nonsmokers' negative perceptions of smokers. 3P3 believes nonsmokers "feel like they're better than you” but rejected this, saying “it doesn't make you inferior or superior if you're a tobacco user or not." Personal-relational gaps also occurred with nonsmoking friends who: ...don't get it either. The nonsmokers. Cause they, they make fun of me too. But there's sometimes when I just need one. I'm really stressed, I haven't had one in like a few hours or something, and I just need a cigarette. And a lot of my friends would tease me about it, and I'm just, ya know, cranky. (1P1)

Despite formerly smoking cigarettes and currently smoking e-cigarettes, $2 \mathrm{P} 1$ feels that some of his friends who smoke cigarettes "assume that I'm judging them but in actuality I was there like a year ago...it's just kind of a weird communication breakdown." Whether the judgment smokers perceive from nonsmokers is real or assumed, for these participants it created a tension between their self-concept and their relationships with nonsmokers. 
Personal-enacted-relational identity gaps. Personal-enacted-relational identity gaps result from differences in an individual's self-concept, the identity he expresses to manage others' impressions, and an ascribed identity that does not match his self-concept. Eighteen instances of personal-enacted-relational identity gaps were expressed by 10 participants, demonstrating the complexity of identity management surrounding smoking. Participants often enacted a nonsmoker identity to avoid being ascribed a smoking identity despite personally identifying as a smoker and enacting smoking behavior. When asked whether he identifies as a smoker 3P1 said "yeah, to myself but if people ask me (.) no. Like, doctor, you smoke drink? 'No.' Parents, 'no,' anybody older than me, 'no.' I don't want to be looked at as a smoker.’ 3P3 would avoid telling old friends who "I always told I'm gonna quit" about his smoking. He reasoned that if they saw him smoking now "God, they probably think I'm still just like the little old [me] just smokin' a cig, ya know, not doin' anything, ditching class."

Personal-enacted-relational gaps also occurred when participants avoided disclosing their smoking to romantic partners out of concern that it would change their partners' perceptions of them. During his heaviest period of smoking 3P1 recalled thinking:

Wow (.) that's really bad, like, why? Why are you doing this, if, you looked at yourself three years ago, like, you would be disgusted with yourself ... you broke up with your girlfriend and imagine if she saw you smoking cigarettes now she'd be like 'ew, I'm glad he broke up with me' and I was missing her so I was just like 'God I'm just a piece of shit.' But (.) would just hide it more then.

\section{Strategies for Managing Gaps in the Relational Layer of Identity}

As illustrated in the previous section, relational identity is strained by smoking. Young adult smokers attempt to manage this strain to reduce the burden of smoking on their 
relationships. To better understand this phenomenon, research question two asked what strategies young adult smokers use to manage identity gaps resulting from their smoking. We uncovered four strategies: being considerate of others when smoking, concealing the smell of smoking, gauging others' reactions to smoking prior to disclosing their own smoking status, and deceiving relational others.

Be considerate. Smokers held themselves to specific smoking etiquette standards that can be broadly described as "being considerate" to counteract some of the negative stigmas related to smoking. 2P2 recognized a need to "be respectful. It doesn't cost me anything to respect these social standards" (e.g., smoke away from others in designated areas, do not litter cigarette butts). 4P5 summarized his rules about when and where it is appropriate to smoke as “revolving around courtesy I guess? I really try not bother people who aren't okay with it and I have to assume that the average passer-by won't be okay with it." $3 \mathrm{P} 2$ has "never encountered a problem in my own personal social groups," which he attributes to being polite and smoking in designated areas. IP4 imagines that if someone objected to her smoking she would "try to be more respectful of them and try to be polite to them and not do that in front of them."

Concealment. Participants cited the smell of cigarettes as the most obnoxious aspect of smoking. The "bitter smell" was described as "the only evidence that you have smoked" and for this reason IP7 believed "a lot of people would hide the smell... If I don't smell like a smoker and I'm not smoking how do you know I am one?" One participant switched to e-cigarettes because "I can feel the pressure people give me when I smoke a cigarette and go into class and I have people sitting next to me? I get it cause it's kinda obnoxious the smell? ... I don't wanna be being obnoxious" (IP5). 1P2 avoids smoking around his friends noting that "I don't like the smell of it 
[cigarettes] either, I know they don't. So I don't smoke in the car with friends, I don't make friends wait for me, it's pretty much always by myself."

Gauge relational others' reactions. To avoid relational identity gaps participants attempted to gauge others' reactions to smoking before disclosing their smoking. Some would "try to bring it [smoking] up casually in a non-related to me sort of way... just to get them to commentate on it and to see how they feel about it" (IP4). Similarly, 4P5 is "inclined not to tell" nonsmokers about his smoking until he "can feel it out and see if they're okay with it ... on my own versus saying it and then possibly getting a negative reaction." People usually uncover IP7's smoking before he can purposefully disclose but he can "definitely see keeping it back until you can gauge your audience ... see what their reaction would be."

Deception. When close relations uncovered participants' smoking, some participants lied to avoid identity gaps. IP5 was caught smoking several times by his parents but reported that "the time I quit for two years? That's the last time they think I smoked." IP1 said he would deliberately not tell his mother about his smoking even though she "already knows but I would tell her that I'd quit." Under the influence of alcohol, 3P1 told his mother that he smoked cigarettes but when she confronted him the next morning he replied, "oh, no, like I- I just have like one or two when I'm drinking occasionally, it's not a big deal, I'm gonna stop, I don't like it."

\section{Discussion}

Guided by the communication theory of identity, this study uncovered relational identity gaps experienced by young adult smokers. Participants experienced, and in some cases, chose to perpetuate, relational identity gaps largely to avoid being ascribed the negative characteristics associated with smokers. To avoid the ascription of a smoker identity and likely occurrence of 
personal-relational identity gaps, participants communicated nonsmoking identities to family members, romantic partners, and authority figures. While enacting a nonsmoking identity may have prevented personal-relational gaps, it often resulted in enacted-relational gaps, the most prevalent identity gap in this sample. Personal-enacted-relational gaps arose when participants personally identified as smokers yet enacted a nonsmoking identity with relational partners to avoid being ascribed a smoker identity.

Young adult smokers described attempts to maintain enacted-relational and personalrelational identity gaps to avoid the negative stereotypes associated with being a smoker. Smokers are likely to experience stigmatization and subsequent identity gaps because of the widespread de-normalization of smoking and smoke-free legislation. Though de-normalization policies have been credited for decreasing rates of smoking (Kim \& Shanahan, 2003) others have criticized the perhaps unintended effects of de-normalization on the stigmatization of smokers (Bayer \& Stuber, 2006). In the balancing act of de-normalization we must be sure that the stigmatization of smoking does not become so great that smokers will not disclose their smoking status to relational others, including physicians, who may help them change their behavior, as was the case among this sample. Burris' (2008) endorsement of emphasizing the negative aspects of smoking while condemning the use of stigma for social control is a useful guideline.

Personal-relational identity gaps arise when people are unable to integrate an aspect of their identity into their relationships. Young adult smokers who experienced personal-relational identity gaps demonstrated difficulty integrating their smoking into their socially informed roles (e.g., son, boyfriend). It may be that the characteristics associated with smoking are incompatible with the more positive characteristics associated with other relational roles. Bringing a devalued identity into an identity co-developed with another may also damage the identity of the other. For 
example, a son disclosing to his mother that he smokes may cause the mother to reevaluate her relationship with her son or reevaluate her own role as a mother. In this case, it is fear of damaging the relational other's identity that drives the person to avoid disclosing his or her smoking. However, by not disclosing to relational others the smoker is unable to receive social support for cessation and is at risk for decreased relationship satisfaction (Jung, 2011).

Identity gaps were originally theorized as producing a drive to minimize their magnitude (Jung \& Hecht, 2004). In this case however, participants chose to maintain enacted-relational gaps through communicative and behavioral means. It is important to note that non-disclosure of an identity is only an identity gap when the individual recognizes the discrepancy between the identity they are communicating and the identity they are constructing with the relational other. Less understood are other ways that layers of identity interact, for example, they may somehow enhance each other. Though dissonance and tension may not accompany all instances of identity gaps, most research has demonstrated that identity gaps "are problematic for people by creating tension or stress" (Wadsworth, Hecht, \& Jung, 2008, p. 68).

Although maintaining or maximizing an identity gaps has not been closely examined in CTI research, some evidence points toward the possibility (Brooks \& Pitts, 2016). Kam and Hecht (2009) suggest that there may be positively valenced identity gaps. For example, identity gaps may be desirable for individuals who want to avoid being ascribed a stereotypic identity in favor of a more nuanced personal identity (Brooks \& Pitts, 2016). In our case, smokers may desire to maintain identity gaps implicating the relational layer of identity if maintaining relational harmony is more important to them than reducing the dissonance of an identity gap. Personal-relational identity gaps are inversely associated with communication satisfaction, feeling understood, communication appropriateness, communication effectiveness, and level of 
depression (Jung \& Hecht, 2004, 2008). Still, a smoker may be willing to deal with these negative outcomes if he or she perceives relational problems to be more distressing. Maintenance of certain gaps may also prevent other types of identity gaps from arising. Individuals may therefore choose to maintain one identity gap to preserve coherency in other layers of identity, but there may be long-term implications of such a strategy. Future research to determine at what point the discomfort associated with identity gaps outweighs the benefits of maintaining them would be useful in learning how to induce behavior change because of identity gaps.

This study offers the possibility for several practical applications. Findings point to the importance of targeting relational partners to encourage behavior change rather than targeting smokers directly. In theorizing the potential for identity gaps to influence behavior, Hecht and Choi (2012) suggest that drawing attention to identity gaps could increase dissonance and motivate behavior change. Therefore, in order to motivate behavior change in response to identity gaps the degree of gaps and their social implications should be targeted in order to increase their magnitude. Targeting the strategies participants used to manage identity gaps may increase the degree and social implications of identity gaps. For example, health care providers might decrease young adult smokers' ability to engage in deception by consistently asking about their smoking status, thereby increasing the degree of enacted-relational identity gaps.

Many of the strategies that young adult smokers reported aimed at hiding or delaying their smoking from relational others. In some cases, young adult smokers reported gauging relation others' reactions to smoking before choosing whether to disclose their smoking. Choosing whether, when, and with whom to disclose a stigmatized identity is an option available to those who have stigmatized yet concealable identities (Faulkner \& Hecht, 2011). Young adult smokers' attempts at hiding their smoking make a strong network of interpersonal contacts even 
more important. Rather than attempting to persuade young adult smokers to disclose their smoking to relational others it may be more useful to promote topic initiation to relational partners of potential smokers. Nonsmoking relational partners who could act as nonsmoking allies might include romantic partners, parents, and doctors.

In addition to relational strain with close personal others, some young adult smokers avoid disclosing their smoking status to their health care providers and thus maintain enactedrelational identity gaps. Young adults' reluctance to disclose their smoking identity is recognized in the term "phantom smoker" or "deniers" and is more likely among college students (Leas, Zablocki, Edland, \& Al-Delaimy, 2015). This finding is especially troubling given that receiving advice from a health care provider is correlated with pharmacotherapy use for smoking cessation among young adults (Curry, Sporer, Pugach, Campbell, \& Emery, 2007). The reluctance of young adults to disclose their smoking status seems to be mirrored by health care providers' reluctance to ask about smoking status. Young adult smokers are less likely to be asked about their smoking or receive advice to quit from health care providers than smokers of other age groups (Curry et al., 2007). Interventions ensuring that health care providers at least ask about their patients' smoking status may increase the likelihood that young adults actually disclose their smoking identity with health care providers rather than maintain identity gaps. Health care providers might ask "would you say you're a social smoker, non-smoker, occasional smoker?" (Leas et al., 2015, p. 402). Providing a wider range of smoking identities, some of which are less stigmatized than others, may provide opportunities for health care providers to deliver smoking cessation counseling.

\section{Limitations}


Recruitment was a limitation of this study. Only two women participated in the study compared to 18 men. While smoking prevalence is slightly higher among men than women (Jamal et al., 2016), we might still expect more female participants. There was nothing in the recruitment materials that would have appealed to men over women. Instead, the lack of female participants indicates that women who smoke may be particularly stigmatized. Indeed, women smokers perceive a "smoking double standard" where women's smoking is seen as less desirable and less acceptable than men's smoking (Triandafilidis, Ussher, Perz, \& Huppatz, 2017, p. 1450). However, the two female participants (one e-cigarette user, one cigarette smoker) appeared to experience less tension resulting from their smoking, generally recounting fewer identity gaps than the males in the group. Future research should explore whether women who smoke experience identity gaps involving the relational layer of identity, and whether they experience relational identity gaps in ways that are similar to men. Additionally, future research using focus group methodology should include a follow up session to determine whether such discussions stimulate positive behaviors in the future.

\section{Conclusion}

This study used communication theory of identity to examine the impact of smoking on young adult cigarette and e-cigarette smokers' interpersonal relationships. Multiple identity gaps implicating the relational layer were revealed, as well as strategies young adults use to avoid and, in some cases, maintain relational gaps. Maintenance of identity gaps, while rarely explored in research, suggests that young adult smokers engage in complex identity work to negotiate their identity as a smoker. In some cases, negotiation requires maintaining tension and dissonance between layers of identity, though the long term negative effects of such tension might prove untenable. This study offers points of intervention for future health messages and behavior 
change strategies to target. It is our hope that by uncovering how smoking complicates relationships in young adult smokers' interpersonal lives more interventions targeting the relational level of identity will be attempted to stimulate behavior change among young adult smokers. 


\section{References}

Arnett, J. J. (2000). Emerging adulthood: A theory of development from the late teens through the twenties. American Psychologist, 55, 469-480. doi:10.1037/0003-066X.55.5.469

Bayer, R., \& Stuber, J. (2006). Tobacco control, stigma, and public health: Rethinking the relations. American Journal of Public Health, 96, 47-50. doi:10.2105/AJPH.2005.071886

Berg, C. J., Parelkar, P. P., Lessard, L., Escoffery, C., Kegler, M. C., Sterling, K. L., \& Ahluwalia, J. S. (2010). Defining 'smoker': College student attitudes and related smoking characteristics. Nicotine \& Tobacco Research, 12, 963-969. doi:10.1093/ntr/ntq123

Burris, S. (2008). Stigma, ethics and policy: A commentary on Bayer's Stigma and the ethics of public health: Not can we but should we. Social Science and Medicine, 67, 473-475. doi:10.1016/j.socscimed.2008.03.020

Coleman, B. N., Johnson, S. E., Tessman, G. K., Tworek, C., Alexander, J., Dickinson, D. M., \& ... Green, K. M. (2015). 'It's not smoke. It's not tar. It's not 4000 chemicals. Case closed': Exploring attitudes, beliefs, and perceived social norms of e-cigarette use among adult users. Drug and Alcohol Dependence, 159, 80-85. doi:10.1016/j.drugalcdep.2015.11.028

Curry, S. J., Sporer, A. K., Pugach, O., Campbell, R. T., \& Emery, S. (2007). Use of tobacco cessation treatments among young adult smokers: 2005 National Health Interview Survey. American Journal of Public Health, 97, 1464-1469. doi:10.2105/AJPH.2006.103788

Faulkner, S. L., \& Hecht, M. L. (2011). The negotiation of closetable identities: A narrative analysis of lesbian, gay, bisexual, transgendered queer Jewish identity. Journal of Social \& Personal Relationships, 28, 829-847. doi:10.1177/0265407510391338 
Festinger, L. (1962). Cognitive dissonance. Scientific American, 207, 93-107. doi:10.1038/scientificamerican1062-93

Freedman, K. S., Nelson, N. M., \& Feldman, L. L. (2012). Smoking initiation among young adults in the United States and Canada, 1998-2010: A systematic review. Preventing Chronic Disease, 9, doi:10.5888/pcd9.110037.

Glaser, B. (1978). Advances in the methodology of grounded theory: Theoretical sensitivity. Mill Valley, CA: The Sociology Press.

Hecht, M. L. (1993). 2002—a research odyssey: Toward the development of a communication theory of identity. Communication Monographs, 60, 76-82. doi:10.1080/03637759309376297

Hecht, M. L. (2014). Communication theory of identity: Multilayered understandings of performed identities. In D. O. Braithwaite, \& P. Schrodt (Eds.), Engaging theories in interpersonal communication: Multiple perspectives (pp. 175-187). Los Angeles, CA: Sage Publication.

Hecht, M. L., \& Choi, H. (2012). The communication theory of identity as a framework for health message design. Health Communication Message Design: Theory and Practice. Los Angeles, CA: Sage, 137-152.

Jamal, A., King, B. A., Neff, L. J., Whitmill, J., Babb, S. D., \& Graffunder, C. M. (2016). Current cigarette smoking among adults - United States, 2005-2015. Morbidity and Mortality Weekly Report, 65, 1205-1211. Retrieved from: http://dx.doi.org/10.15585/mmwr.mm6544a2 
Jung, E., \& Hecht, M. L. (2004). Elaborating the communication theory of identity: Identity gaps and communication outcomes. Communication Quarterly, 52, 265-283. http://dx.doi.org/10.1080/01463370409370197

Jung, E., \& Hecht, M. L. (2008). Identity gaps and level of depression among Korean immigrants. Health Communication, 23, 313-325. doi:10.1080/10410230802229688

Kam, J. A., \& Hecht, M. L. (2009). Investigating the role of identity gaps among communicative and relational outcomes within the grandparent-grandchild relationship: The young-adult grandchildren's perspective. Western Journal of Communication, 73, 456-480. doi:10.1080/10570310903279067

Kearney, M. H., \& O'Sullivan, J. (2003). Identity shifts as turning points in health behavior change. Western Journal of Nursing Research, 25, 134-152. doi: $10.1177 / 0193945902250032$

Kim, S., \& Shanahan, J. (2003). Stigmatizing smokers: Public sentiment toward cigarette smoking and its relationship to smoking behaviors. Journal of Health Communication, 8 , 343-367. doi:10.1080/10810730390223371

Leas, E. C., Zablocki, R. W., Edland, S. D., \& Al-Delaimy, W. K. (2015). Smokers who report smoking but do not consider themselves smokers: A phenomenon in need of further attention. Tobacco Control, 24, 400-403. doi:10.1136/tobaccocontrol-2013-051400

McCool, J., Hoek, J., Edwards, R., Thomson, G., \& Gifford, H. (2013). Crossing the smoking divide for young adults: Expressions of stigma and identity among smokers and nonsmokers. Nicotine \& Tobacco Research, 15, 552-556. doi:10.1093/ntr/nts136

Moran, M. B., \& Sussman, S. (2014). Translating the link between social identity and health behavior into effective health communication strategies: An experimental application 
using antismoking advertisements. Health Communication, 29, 1057-1066.

doi:10.1080/10410236.2013.832830

O’Reilly, M., \& Parker, N. (2012). 'Unsatisfactory saturation': A critical exploration of the notion of saturated sample sizes in qualitative research. Qualitative research, 13, 190197. doi: $10.1177 / 1468794112473497$

Pettigrew, J., Miller-Day, M., Krieger, J., \& Hecht, M. L. (2011). Alcohol and other drug resistance strategies employed by rural adolescents. Journal of Applied Communication Research, 39, 103-122. doi:10.1080/00909882.2011.556139

Phua, J. (2013). Participating in health issue-specific social networking sites to quit smoking: How does online social interconnectedness influence smoking cessation self-efficacy?. Journal of Communication, 63, 933-952. doi:10.1111/jcom.12054

Rath, J. M., Villanti, A. C., Abrams, D. B., \& Vallone, D. M. (2012). Patterns of tobacco use and dual use in U.S. young adults: The missing link between youth prevention and adult cessation. Journal of Environmental and Public Health, 1-9. doi:10.1155/2012/679134

Ritchie, D., Amos, A., \& Martin, C. (2010). 'But it just has that sort of feel about it, a leper'-Stigma, smoke-free legislation and public health. Nicotine \& Tobacco Research, 12, 622629 doi:10.1093/ntr/ntq058

Rubin, H. J., \& Rubin, I. S. (1995) Qualitative interviewing: The art of hearing data. Thousand Oaks, CA: Sage Publications.

Saldaña, J. (2014). Coding and analysis strategies. In P. Leavy, P. Leavy (Eds.), The Oxford handbook of qualitative research (pp. 581-605). New York, NY: Oxford University Press. 
Singh, T., Arrazola, R.A., Corey C.G., Husten, C. G., Neff, L. J., Homa, D. M., \& King, B. A. (2016). Tobacco use among middle and high school students — United States, 20112015. Morbidity and Mortality Weekly Report 65, 361-367. doi:10.15585/mmwr.mm6514a1

Stanley, S. J. (2016). Targeting young adult smokers' multiple identity gaps and identity management strategies for behavior change: An application of the communication theory of identity. Retrieved from ProQuest Dissertations \& Theses Global. (AAT 10119246).

Tombor, I., Shahab, L., Herbec, A., Neale, J., Michie, S., \& West, R. (2015). Smoker identity and its potential role in young adults' smoking behavior: A meta-ethnography. Health Psychology, 34, 992-1003. doi:10.1037/hea0000191

Tracy, S. J. (2013). Qualitative research methods: Collecting evidence, crafting analysis, communicating impact. Malden, MA: Wiley-Blackwell.

Triandafilidis, Z., Ussher, J. M., Perz, J., \& Huppatz, K. (2017). An intersectional analysis of women's experiences of smoking-related stigma. Qualitative Health Research, 27, 14451460. doi:10.1177/1049732316672645

U.S. Department of Health and Human Services, Centers for Disease Control and Prevention, National Center for Chronic Disease Prevention and Health Promotion, Office on Smoking and Health. (2016). E-cigarette use among youth and young adults: A report of the Surgeon General. Retrieved from: https://ecigarettes.surgeongeneral.gov/documents/2016_SGR_Full_Report_non-508.pdf

Wadsworth, B. C., Hecht, M. L., \& Jung, E. (2008). The role of identity gaps, discrimination, and acculturation in international students' educational satisfaction in American classrooms. Communication Education, 57, 64-87. doi:10.1080/03634520701668407 
Wang, C., Hipp, J. R., Butts, C. T., Jose, R., \& Lakon, C. M. (2016). Coevolution of adolescent friendship networks and smoking and drinking behaviors with consideration of parental influence. Psychology of Addictive Behaviors, 30, 312-324. doi:10.1037/adb0000163 